\title{
Occurrence of vocal changes in preschoolers with no voice complaints: an auditory-perceptual and acoustic analysis
}

\author{
Gabriela Samanttha Cavalcanti do Nascimento' \\ https://orcid.org/0000-0001-8002-8588 \\ Giselle Frutuoso do Nascimento' \\ https://orcid.org/0000-0001-6278-1197 \\ Juliana Fernanda Dias da Silva ${ }^{1}$ \\ https://orcid.org/0000-0002-5092-8195 \\ Sandro Júnior Henrique Lima ${ }^{1}$ \\ https://orcid.org/0000-0003-3257-2604 \\ Zulina Souza de Lira ${ }^{1}$ \\ https://orcid.org/0000-0002-8413-5513
}

Adriana de Oliveira Camargo Gomes ${ }^{1}$

https://orcid.org/0000-0002-1871-9502

Universidade Federal de Pernambuco, Recife, Pernambuco, Brasil.

Research support source: Coordenação de Aperfeiçoamento de Pessoal de Nível Superior - Brasil - CAPES. Finance Code 001 and Pró-Reitoria de Pós-Graduação da Universidade Federal de Pernambuco.

Conflict of interests: Nonexistent



\section{ABSTRACT}

Purpose: to verify, with the auditory-perceptual and acoustic parameters, the occurrence of voice changes in children with no voice complaints, per sex.

Methods: the registers of 36 children with no voice complaints, aged 6 to 8 years, of whom 19 were males, were assessed. The databank consisted of the recordings of sustained vowels, sentences, and spontaneous speech. The auditory-perceptual analysis was conducted with the Consensus Auditory-Perceptual Evaluation of Voice, and the acoustic analysis, with VoxMetria. The fundamental frequency, jitter, shimmer, noise, and glottal-to-noise excitation ratio were analyzed. The Mann-Whitney test was applied for numerical variables, and the McNemar test, for the categorical ones, at the $p<0.05$ significance level.

Results: of the 5 children with mild voice changes, 4 were males. The most frequent resonance deviation was the laryngopharyngeal one. There was no difference between the sexes in the auditory-perceptual findings. The fundamental frequency in the group with changes was lower than that in the group without changes. There was a statistical association between the changes in the auditory-perceptual assessment and the acoustic parameters.

Conclusion: voice changes occurred in $13.89 \%$ of the studied sample of children with no voice complaints, without differences between the sexes in the auditory-perceptual parameters. Vocal deviations were in a mild degree in all children who had them, the most frequent ones being roughness and breathiness. The fundamental frequency and shimmer were the acoustic parameters whose values most often occurred outside the reference limits, in both genders.

Keywords: Child; Dysphonia; Voice Disorders; Voice 


\section{INTRODUCTION}

Voice is a complex human communication tool, produced based on muscular, acoustic, psychosocial, and physiological parameters, and cultural and individual habits ${ }^{1,2}$. The quality of voice has a strong influence on social capacity and skills. Hence, considering the said parameters as inseparable variables of the production process, raising awareness, and intervening in the vocal behavior have consequences that go beyond the sound aesthetics ${ }^{3}$. When dealing with children, the practice must be guided by the premise that the child's voice has a specific complexity involving behavioral, physiological, and cognitive aspects ${ }^{4,5}$.

The child's voice has particularly different characteristics from the adult one. These are not only related to laryngeal structural differences and its relative position in the neck, but also to the instabilities caused by the growth and development process, which reflects on muscular and respiratory adjustments that interfere with voice quality. Therefore, discrete degrees of hoarseness and breathiness are to be expected in children ${ }^{1,5-7}$.

The concept of child dysphonia is any difficulty that prevents or hinders children's natural voice production because of poor adjustments in it, which in turn may result from inadequate vocal behavior or anatomic, physiological, social, and/or environmental imbalance. It is oftentimes associated with other etiologies, ranging from self-limiting maladies to different degrees of incapacitating changes that require more incisive interventions ${ }^{8,9}$.

The formation of children's voice patterns can be influenced by the environment and culture to which the child belongs. Thus, the child voice in institutional settings, including preschool, raises frequent concern ${ }^{10}$ because such environments promote an abusive vocal behavior common to children ${ }^{2,11}$, caused, among other things, by environmental noise ${ }^{10}$. The characteristics of the family are also pointed out as ones that lead to the development and practice of either adequate or inadequate vocal habits, such as yelling, speaking loudly, speaking excessively, strained vocalizations, and so on ${ }^{4,7,12-15}$.

Studies demonstrate that changes in preschoolers' vocal behavior are determining factors for dysphonia in them, and that voice disorders have been increasing in recent decades, along with the frequency of vocal abuse in boys and girls ${ }^{2,4,16}$.

The range of etiological factors related to child dysphonia requires a correct and early diagnosis which is not always possible due to various factors.
One of these is taking too long to seek help from health professionals, due to little concern on the part of the parents regarding their child's voice changes, as the children do not have quite alarming symptoms involving other systems ${ }^{17}$.

Therefore, the children's voice assessment with auditory-perceptual and acoustic analysis may provide the means for interventions aiming at this population's vocal health care and the parents' and teachers' awareness of the importance of the children's voice quality.

Hence, this study aimed to verify the occurrence of voice changes and their auditory-perceptual and acoustic parameters in preschoolers, with no voice complaints, per sex.

\section{METHODS}

This cross-sectional, quantitative, retrospective study with descriptive analysis was approved by the Human Research Ethics Committee of the Department of Health Sciences at the Universidade Federal de Pernambuco (Federal University of Pernambuco), Brazil, under evaluation report number 1.668.792.

The research was based on secondary data, previously stored in computer vocal register databases, where the voices were recorded at sample rates of 44 $\mathrm{kHz}$ in the VoxMetria and Fonoview software, from CTS Informática. The recordings consisted of the emission of sustained $/ \mathrm{a} /, / \varepsilon /$, and $/ \mathrm{i} /$ vowels in habitual voice for approximately five seconds, standardized sentences of the CAPE-V protocol, and spontaneous conversation. The six preestablished sentences aimed to elicit various laryngeal behaviors and clinical signs (phrases with stop, fricative, and nasal phonemes). The spontaneous conversation consisted of a speech of at least 20 seconds, elicited by the examiner, on subjects related to children's daily life.

The study's inclusion criteria encompassed all the vocal registers of children with no voice complaints, enrolled in a preschool, aged 6 to 8 years - which was the age of those who attended the institution where the study was carried out. Also, restricting the age range allowed for a more biologically homogeneous sample, considering the growth and development of the larynx and vocal tract, when the anatomical conditions of the larynx are similar (keeping in mind the quick changes that take place in these structures) and the differences between the sexes are not yet significant ${ }^{1,5,7,17,18}$. Due to these quick differentiations in the morphology of the vocal tract and consequently the voice quality, other 
studies have also researched restricted age groups ${ }^{8,18}$. Children whose registers were incomplete were excluded from the study.

Thus, the assessment encompassed the vocal register of 36 children with no voice complaints, aged 6 to 8 years, both females $(n=17)$ and males $(n=19)$, upon authorization from their parents, who signed the informed consent form.

The auditory-perceptual assessment consisted of the subjective impression of the person's voice quality, with the Consensus Auditory-Perceptual Evaluation of Voice (CAPE-V) ${ }^{19}$. The CAPE-V was fully used, with the emission of the vowels, the six sentences, and the spontaneous speech.

The application of CAPE- $V$ indicates changes in vocal perceptual attributes, counting its degree of change. The attributes are overall severity, roughness, breathiness, strain, pitch change, loudness change, two spaces for other possible changes in voice quality, and classification of the vocal resonance as normal or changed.

The CAPE-V presents each attribute accompanied by a 100-millimeter line, forming a visual analog scale, and establishing a percentual score for each parameter analyzed. With markings, the assessors indicated the degree of perception from normal to deviant for each parameter in the scale.

To count the points, the assessor physically measured the distance in millimeters from the left to the end of the scale. The score was noted in the blank space on the right side of the table, together with the total proportion of the $100-\mathrm{mm}$ length of the line. The results were analyzed, considering the deviations and degrees of voice change.

A file was created for the auditory-perceptual assessment containing all the voice samples, adding $10 \%$ of random repetition for intra-assessor reliability analysis, totaling 40 voices. The samples were randomly numbered with the Intemodino Group's Random Number Generator (http://randomnumbergenerator.intemodino.com/pt/gerador-de-numerosaleatorios.html) to ensure that the voices were blinded in the assessment and reassessment.

Three speech-language-hearing therapists specialized in voice, with over 10 years of auditoryperceptual analysis and clinical experience, were invited to voluntarily participate in the research with independent and blind judgment, with no financial gratification or co-authorship in publication. The assessors were sent the file with the voices recorded in a CD.
Hence, they analyzed all the 40 voices - i.e., all the vocal registers of the 36 subjects of the research, plus four random repetitions. In the analysis, only the first register of the repeated files was considered. The intraand inter-judge agreement of the auditory-perceptual analysis variables was assessed with the intraclass correlation coefficient (ICC), equivalent to the kappa statistics for continuous variables. In all the cases, the level of agreement was satisfactory $($ ICC $=0.66)$.

Each assessor was instructed to assess the samples playing the voice files individually as many times as necessary, in a quiet room, with an earphone, at comfortable intensity, and fill out the CAPE-V protocol related to each sample. They were also requested to analyze up to 10 voice samples a day, for its fatigue not to interfere with the quality of the assessment.

The acoustic analysis was conducted with the VoxMetria program, from CTS Informática, analyzing the following parameters: mean fundamental frequency (and its variations - jitter and shimmer), noise measurement, and glottal-to-noise excitation ratio (GNE), based on the recording of the sustained / $/ \square /$ vowel.

The CAPE-V scores were used in the auditoryperceptual analysis. The value obtained for each child in each of the parameters was calculated based on the mean values given by the three judges. Markings higher than zero in the assessment of at least two judges in the auditory-perceptual analysis were used to verify the occurrence of any degree of deviation in voice parameters.

The scores established for adults - namely: 0-34 $\mathrm{mm}$ (neutral degree), 34.1-51 $\mathrm{mm}$ (mild degree), 51.1-63.5 (moderate degree) - were used to assess the degree of vocal deviation. Based on these scores, the children were divided into two groups: neutral change and mild change ${ }^{20}$. The mean of the groups was calculated by summing the mean values obtained for each child, divided by the number of subjects in that group. The results of the groups with neutral and mild change were also stratified by sex.

The acoustic analysis program presents the reference values for jitter, shimmer, and GNE noise measure to compare the data with normal parameters, namely: jitter $=0.5 \%$, shimmer $=6.5 \%$, and GNE $=0.5$ $\mathrm{dB}$. These are the parameters considered to analyze the adult voice.

The data normality was analyzed with the Shapiro-Wilk test, rejecting the hypothesis of a normal distribution when $p<0.05$. Pearson's chi-squared 
test, or Fisher's exact test, was used to verify the statistical association between the changes in the auditory-perceptual assessment and acoustic analysis. The Mann-Whitney test was used in the comparison between the sexes in the analysis of the numerical variables of the acoustic and auditory-perceptual assessment, while the McNemar test was used in the analysis of the categorical variables (with and without change), all of them at the $5 \%$ significance level.

\section{RESULTS}

Figure 1 presents the occurrence of voice changes in relation to the overall severity and the voice parameters analyzed with the auditory-perceptual assessment. The percentages were calculated based on the total number of children of each sex - hence, the values presented for each parameter do not add up to $100 \%$.

$80 \%$

$60 \%$



Figure 1. Occurrence of children identified with deviations in the voice parameters, according to the auditory-perceptual analysis, stratified by sex

Voice changes were observed in $13.89 \%$ of the children with no voice complaints, with a mild change degree.

The results of the voice analysis regarding the resonance patterns are given in Figure 2. Most of the children had a balanced resonance pattern, and the most frequent resonance deviation was the laryngopharyngeal one.
Each child's mean values of the degree of change were tabulated in percentage as given by the three judges. Table 1 shows the mean values of each parameter analyzed in the auditory-perceptual assessment of the children with and without change, according to the classification ${ }^{17}$ that defines values between 0 and $34 \mathrm{~mm}$ as neutral (zero degree). It should be highlighted that the same child may have more than one changed parameter. 




Figure 2. Percentage distribution of the identified resonance patterns, stratified by sex

Table 1. Mean values of the voice parameters and their respective standard deviations, assessed in the auditory-perceptual analysis, classified as neutral and mild change, distributed by sex. $(\mathrm{N}=36)$

\begin{tabular}{|c|c|c|c|c|c|c|c|c|c|c|c|c|c|}
\hline \multirow{2}{*}{ Parameter } & \multicolumn{4}{|c|}{ Mild change } & \multicolumn{4}{|c|}{ No change } & \multicolumn{2}{|c|}{ Mild change } & \multicolumn{2}{|c|}{ No change } & \multirow{2}{*}{$\begin{array}{c}\mathrm{MXF} \\
\mathrm{p}^{*}\end{array}$} \\
\hline & M & $\mathrm{n}$ & $F$ & $n$ & M & $\mathrm{n}$ & $\mathrm{F}$ & $n$ & Total & $n$ & Total & $n$ & \\
\hline $\begin{array}{l}\text { Overall } \\
\text { Severity }\end{array}$ & $\begin{array}{l}40.17 \\
(6.40)\end{array}$ & 4 & $\begin{array}{c}36.00 \\
(-)\end{array}$ & 1 & $\begin{array}{l}18.77 \\
(8.67)\end{array}$ & 16 & $\begin{array}{l}22.84 \\
(7.71)\end{array}$ & 15 & $\begin{array}{l}39.33 \\
(5.85)\end{array}$ & 5 & $\begin{array}{l}20.74 \\
(8.34)\end{array}$ & 31 & \\
\hline Roughness & $\begin{array}{l}42.17 \\
(7.31)\end{array}$ & 2 & - & 0 & $\begin{array}{l}17.63 \\
(9.37)\end{array}$ & 17 & $\begin{array}{l}20.43 \\
(7.93)\end{array}$ & 17 & $\begin{array}{l}42.17 \\
(7.31)\end{array}$ & 2 & $\begin{array}{l}19.03 \\
(8.66)\end{array}$ & 34 & \\
\hline Breathiness & $\begin{array}{l}40.67 \\
(1.89)\end{array}$ & 2 & - & 0 & $\begin{array}{l}17.94 \\
(9.29)\end{array}$ & 17 & $\begin{array}{l}19.98 \\
(8.31)\end{array}$ & 17 & $\begin{array}{l}40.67 \\
(1.89)\end{array}$ & 2 & $\begin{array}{l}18.96 \\
(8.74)\end{array}$ & 34 & 0.543 \\
\hline Strain & - & 0 & - & 0 & $\begin{array}{l}16.04 \\
(7.24)\end{array}$ & 19 & $\begin{array}{l}13.98 \\
(5.19)\end{array}$ & 17 & - & 0 & $\begin{array}{l}15.06 \\
(6.35)\end{array}$ & 36 & \\
\hline Pitch & - & 0 & - & 0 & 0 & 19 & $\begin{array}{c}5.26 \\
(0.68)\end{array}$ & 17 & - & 0 & - & 36 & \\
\hline Loudness & - & 0 & - & 0 & 0 & 19 & 0 & 17 & - & 0 & - & 36 & \\
\hline
\end{tabular}

* Mann-Whitney test - at the $5 \%$ significance level

Caption: $\mathrm{n}=$ number of subjects; $\mathrm{M}=$ male children; $\mathrm{F}=$ female children; $\mathrm{MXF}=$ comparison between the sexes

It is noticed that, of the five children that had mild changes, two had roughness and two, breathiness, the four of them males. The female child with a change in the overall severity obtained a neutral voice change score in the other parameters. However, there was no overall difference between the sexes regarding the auditory-perceptual findings.

Table 2 shows the mean values and their standard deviations of the children's acoustic parameters with and without voice changes, according to the normal parameters, referring to fundamental frequency, jitter, shimmer, GNE, and noise and the figure 3 shows the occurrence of the acoustic parameter values, according to the reference patterns established for the age group

The fundamental frequency of the group with changes is smaller than that of the group without changes. As for the other parameters, jitter and shimmer are the ones that most have changes in both sexes. A statistical association was also observed between the changes in the auditory-perceptual assessment and the changes in jitter $(p=0.013)$ and shimmer $(p=0.027)$. 
Table 2. Mean values (standard deviations) of the fundamental frequency (in Hertz), jitter, shimmer, glottal-to-noise excitation ratio, and noise rate of the 36 children assessed

\begin{tabular}{|c|c|c|c|c|c|c|c|c|c|c|c|c|c|}
\hline \multirow{2}{*}{ Parameter } & \multicolumn{5}{|c|}{ With changes } & \multicolumn{7}{|c|}{ Without changes } & \multirow{2}{*}{$\frac{M X F}{p^{*}}$} \\
\hline & M & $n$ & $F$ & $n$ & Total & $n$ & M & $n$ & $F$ & $\mathrm{n}$ & Total & $n$ & \\
\hline $\mathrm{f}_{0}(\mathrm{~Hz})$ & $\begin{array}{l}221.54 \\
(12.02)\end{array}$ & 15 & $\begin{array}{l}225.24 \\
(17.94)\end{array}$ & 16 & $\begin{array}{l}223.45 \\
(15.23)\end{array}$ & 31 & $\begin{array}{c}256 \\
(6.49)\end{array}$ & 4 & $\begin{array}{c}269.45 \\
(0.00)\end{array}$ & 1 & $\begin{array}{c}258.69 \\
(8.23)\end{array}$ & 5 & 0.669 \\
\hline Jitter (\%) & $\begin{array}{c}0.82 \\
(0.51)\end{array}$ & 3 & $\begin{array}{c}2.84 \\
(1.91)\end{array}$ & 9 & $\begin{array}{c}2.34 \\
(1.88)\end{array}$ & 12 & $\begin{array}{c}0.27 \\
(0.13)\end{array}$ & 16 & $\begin{array}{c}0.26 \\
(0.15)\end{array}$ & 8 & $\begin{array}{c}0.26 \\
(0.14)\end{array}$ & 24 & 0.038 \\
\hline Shim (\%) & $\begin{array}{l}10.23 \\
(2.63)\end{array}$ & 10 & $\begin{array}{l}15.70 \\
(7.58)\end{array}$ & 13 & $\begin{array}{l}13.32 \\
(6.47)\end{array}$ & 23 & $\begin{array}{c}4.84 \\
(1.45)\end{array}$ & 10 & $\begin{array}{c}3.68 \\
(1.60)\end{array}$ & 4 & $\begin{array}{c}4.51 \\
(1.60)\end{array}$ & 14 & 0.066 \\
\hline GNE & $\begin{array}{c}0.39 \\
(0.13)\end{array}$ & 2 & $\begin{array}{c}0.33 \\
(0.11)\end{array}$ & 5 & $\begin{array}{c}0.35 \\
(0.10)\end{array}$ & 7 & $\begin{array}{c}0.76 \\
(0.16)\end{array}$ & 17 & $\begin{array}{c}0.73 \\
(0.10)\end{array}$ & 12 & $\begin{array}{c}0.75 \\
(0.14)\end{array}$ & 29 & 0.117 \\
\hline Noise & $\begin{array}{c}3.11 \\
(-)\end{array}$ & 1 & $\begin{array}{c}3.15 \\
(0.32)\end{array}$ & 4 & $\begin{array}{c}3.14 \\
(0.32)\end{array}$ & 5 & $\begin{array}{c}1.29 \\
(0.71)\end{array}$ & 18 & $\begin{array}{c}1.43 \\
(0.50)\end{array}$ & 13 & $\begin{array}{c}1.35 \\
(0.63)\end{array}$ & 31 & 0.129 \\
\hline
\end{tabular}

* Mann-Whitney test - at the $5 \%$ significance level

Caption: $\mathrm{n}=$ number of subjects; $\mathrm{M}=$ male children; $\mathrm{F}=$ female children; $\mathrm{M}$ XF = comparison between the sexes; shim = shimmer; GNE = glottal-to-noise excitation ratio

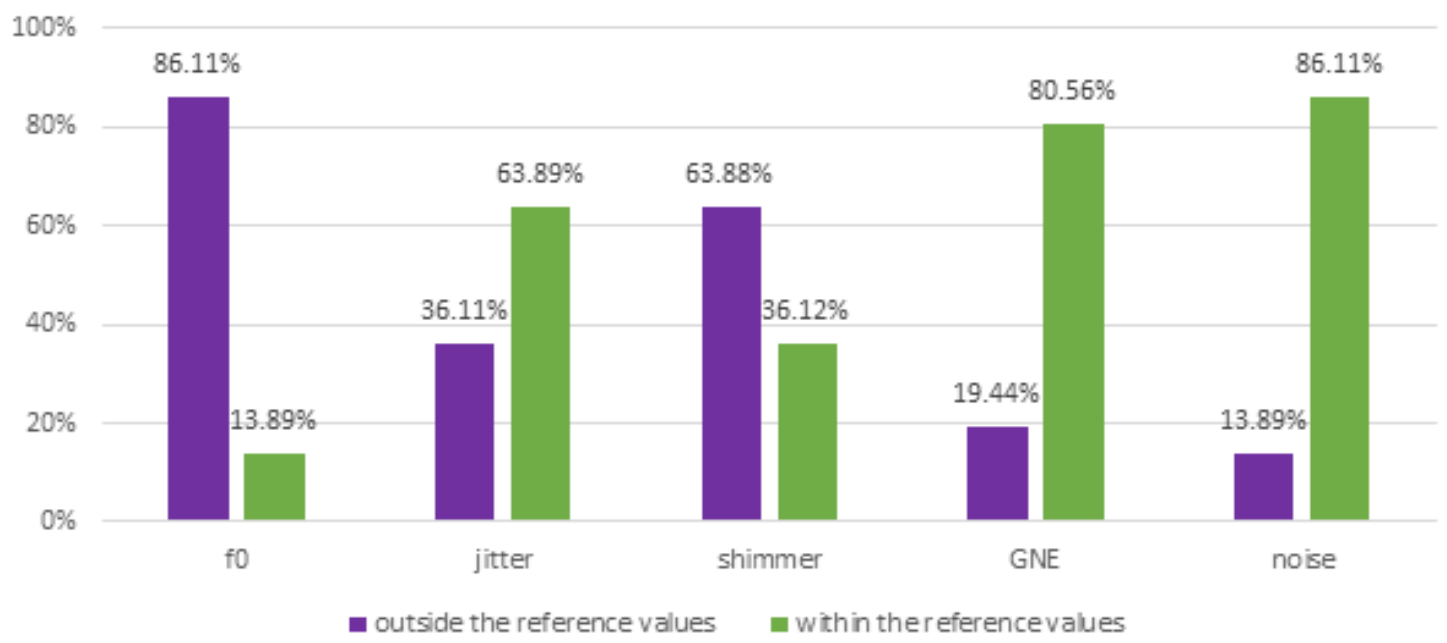

Caption: $\mathrm{f}_{0}=$ fundamental frequency; $\mathrm{GNE}=$ glottal to noise excitation ratio

Figure 3. Occurrence of the acoustic parameter values, according to the reference patterns established for the age group

\section{DISCUSSION}

The auditory-perceptual and acoustic characteristics in the voice of schoolchildren from an assistance and teaching institution were observed in this study. Vocal deviations occurred in $33.89 \%$ of the boys and $24.49 \%$ of the girls, considering the auditory-perceptual analysis. Overall, the vocal deviation occurrence was $13.89 \%$, in a mild degree. Hence, despite being a population with no voice complaints, changes were observed in five children - which corroborates that parents do not perceive changes in their children's voice $^{4,21}$. It also reinforces the occurrence of dysphonia in children 6 to 10 years old, whose most common voice characteristics are roughness and breathiness ${ }^{8}$.

It must be considered that child voice assessment has certain peculiarities, different from that of an adult. Such complexity is also explained by the fact that, besides the few variations between boys' and girls' voice patterns, the concept of voice expected for this population allows for discrete degrees of roughness, breathiness, and nasality, due to the instability inherent to the development process. The maturation of the 
systems that produce phonation is closely related to this instability ${ }^{1,21,22}$. Such a characteristic may have interfered with both the auditory-perceptual assessment and the groups formed with the score classification.

A reflection should be made, though, on the method used. It must be considered that, according to the concept of voice expected for children, discrete degrees of roughness and breathiness are normal ${ }^{1,5,7}$, and that no references have been established in the literature to define the discrete level of change in the children's voices. Also, the reference used for the auditory-perceptual analysis is that of adults, which is a limitation of this study and those on child voice ${ }^{8,18,22}$. Moreover, it was inferred that the assessors, already experienced in auditory-perceptual assessment, considered the concept of voice expected for children, and hence the mild degree of change indeed pointed to a voice change, characterizing the dysphonia ${ }^{8}$.

On the other hand, it must be added that, when considering the reference scores for roughness ${ }^{23}$ on the visual analog scale (such as the CAPE-V), the values from 28.5 up are identified as a moderate degree in adults as well.

Therefore, it is suggested that future studies consider calibrating the judges with child voice models, grading the voice changes based on proper criteria for the voice characteristics expected for the child population, aiming at a greater basis for research with children. Furthermore, the acoustic parameters of the present study pointed to possible changes. Thus, the association of the auditory-perceptual analysis with the acoustic one, the laryngeal examination, and the longitudinal follow-up of these children may better clarify the references to assess this population.

Hence, the parameters established for adults regarding the auditory-perceptual and acoustic assessment must be used with caution when assessing children's voices, even when conducted by judges specialized in voice and with trained ears. Also, it is not always possible to tell the female from the male voices in this population before their voice mutation process starts - which may interfere with the judgment of their voice pitch.

In the overall severity, $24.49 \%$ of the boys and $33.89 \%$ of the girls had a neutral degree. In roughness, $22.05 \%$ of the boys and $21.56 \%$ of the girls had a neutral degree. In breathiness, $27.11 \%$ of the boys and $24.49 \%$ of the girls had a neutral degree. In strain, $16.94 \%$ of the boys and $11.76 \%$ of the girls had a neutral degree. Such findings can also be related to the voice symptoms and the phonatory overload, common to school settings ${ }^{2,21}$.

Male children are expected to have greater voice changes $^{6,8,18}$. However, this study showed that there is no difference between the sexes. In the auditoryperceptual analysis and the acoustic analysis, the girls had more jitter changes than the boys.

Regarding the values of the auditory-perceptual parameters, it was also observed that four male children and one female child had a change in the overall severity. In strain, pitch, and loudness, none of the children had any changes, and the values found were considered neutral. As for the resonance patterns, most of them had no changes. However, the most frequent change was that of laryngopharyngeal resonance, which can either indicate a voice change or predispose to $\mathrm{it}^{24}$.

Nonetheless, as the children were not submitted to laryngoscopy, it cannot be verified whether they had any existing laryngeal pathologies. Therefore, it was necessary to refer them to otorhinolaryngological evaluation and instruct their parents. Such referrals were made following data collection.

As for the acoustic parameters, it is observed that the fundamental frequency is not within the normal standards for children ${ }^{18,24,25}$. Also, it must be considered that the reference values for jitter, shimmer, GNE, and noise are based on parameters for adults. Such values lead to conflicts in the interpretation of these parameters for the children. Hence, it is necessary to establish reference parameters for child population ${ }^{17,22,25-28}$.

An aspect that must be considered is the anatomic difference between children's and adults' vocal folds. The children do not have differentiated layers in the lamina propria, as the adults' do, and therefore their vocal ligament is not yet fully defined ${ }^{5}$. They are also in the phase of neuromuscular development and respiratory support, which can explain greater changes in jitter and shimmer ${ }^{22}$.

The maximum expected values for jitter and shimmer in the program used here are respectively $0.6 \%$ and $6.5 \%$. The values found - respectively $0.73 \%$ and $9.05 \%$ - can be characterized as changed. Thus, of the 36 children, 12 are not within the normal standards for jitter. As for shimmer, only 14 children (38.89\%) had adequate values. It is necessary to compare them with the auditory-perceptual analysis to confirm the impact of these changes on the quality of the children's voice.

The reference value established for the fundamental frequency (f0) of those 6 to 8 years old is 240.02 to 
$249.71 \mathrm{~Hz}^{17,18,25}$. In the group identified with changes, a mean of $223.45 \mathrm{~Hz}$ was observed, which means a value below that established as a reference in children with no voice changes. The most reported explanations for the decrease in fo as one grows older are the anatomical and physiological changes in the laryngeal structures themselves (resulting from normal development) and the maturation of the nervous system, allowing for greater laryngeal control ${ }^{18,25}$. However, f0 values not expected for the age may suggest laryngeal pathologies ${ }^{25}$.

It must be pointed out, though, that the high occurrence of children whose values were different from those established as a reference for this age group (Figure 3) reinforces the need for establishing reference values for the Brazilian child population, based on samples of different regions.

The normal standards for GNE in adult voice, according to the VoxMetria acoustic analysis program, show that $80.56 \%$ of the analyzed children had adequate values ${ }^{24}$.

Based on the findings of this study, further investigation is suggested regarding the child's voice, giving priority to those that already go to school. A limitation in the data analysis is the lack of parameters for children.

The voice analysis computer programs present their parameters' normative values for adults of both sexes, though not for children. Comparative standards must be established with the normal acoustic analysis values in children. The lack of homogeneity in the results of various studies show the importance of carrying out further careful research, enlarging the sample size ${ }^{17}$. Moreover, it is equally important to include younger children in the normative studies because the child's larynx undergoes deep and constant changes from birth to adolescence, and consequently the voice quality increasingly changes parallel to their growth.

The study also reinforces the need for instructing the families and teachers on vocal health and the indispensability of implementing programs for children, aiming to promote knowledge on vocal health, dysphonia, and dysphonia prevention.

Parents and other relatives have an essential role in the children's vocal conditions and can influence child dysphonia. Despite such influence, parents and teachers either pay little attention to voice changes in childhood or do not notice them, thus delaying the intervention ${ }^{4,6,29,30}$. Parents often believe that voice changes in children are temporary or do not have an impact on their child's social relations. Hence, they frequently do not seek the necessary treatment and leave this responsibility to other health professionals and the teachers as well .

Such findings corroborate the importance of programs to promote vocal health in school settings and prevent child dysphonia, as well as instruct the parents and educators.

\section{CONCLUSION}

Voice changes occurred in $13.89 \%$ of the studied sample of children with no voice complaints, without differences between the sexes in the auditoryperceptual parameters. However, there was a greater change in the girls in one of the acoustic parameters. Vocal deviations were in a mild degree in children with this condition, with roughness and breathiness as their predominant voice qualities. The fundamental frequency and shimmer were the acoustic parameters whose values most often occurred outside the reference limits for the age in both sexes.

\section{ACKNOWLEDGMENTS}

The present paper was carried out with support from the Coordenação de Aperfeiçoamento de Pessoal de Nível Superior - Brasil (CAPES) - Finance Code 001 and from the Pró-Reitoria de Pós-Graduação da Universidade Federal de Pernambuco (PROPG-UFPE).

\section{REFERENCES}

1. Aronson $A E$, Bless $D M$. Clinical voice disorders. 4ed. New York: Thieme, 2009.

2. Guerra ASHS, Araujo ANB, Lira ZS, Lucena JA, Gomes AOC. Vocal behavior of children in early childhood education center. Distúrb. Comun. 2014;26(1):101-9.

3. Silva M, Batista AP, Oliveira JP, Dassie-Leite AP. Habilidades sociais em crianças disfônicas. J Soc Bras Fonoaudiol. 2012;24(4):361-7.

4. Paixão CLB, Silvério KCA, Berberain AP, Mourão LF, Marques JM. Disfonia infantil: hábitos prejudiciais à voz dos pais interferem na saúde vocal de seus filhos? Rev. CEFAC. 2012;4(4):705-13.

5. Sapienza CM, Ruddy BH, Baker S. Laryngeal structure and function in the pediatric larynx: clinical applications. Lang Speech Hear Serv Sch. 2004;35(4):299-307. 
6. Tavares ELM, Brasolotto A, Santana MF, Padovan CA, Martins RHG. Epidemiological study of dysphonia in 4-12 year-old children. Braz J Otorhinolaryngol. 2011;77(6):736-46.

7. Gomes AOC, Queiroga BAM, Cunha DA, Pinto DG, Silva HJ, Muniz LF. O desenvolvimento da comunicação na segunda infância e adolescência. In: Queiroga BAM, Gomes AOC, Silva HJ (orgs). Desenvolvimento da comunicação humana nos diferentes ciclos de vida. Barueri: Pró-Fono, 2015. p.121-46.

8. Oliveira RC, Teixeira LC, Gama ACC, Medeiros AM. Análise perceptivo-auditiva, acústica e autopercepção vocal em crianças. J Soc Bras Fonoaudiol. 2011;23(2):158-63.

9. Ribeiro VV, Leite APD, Filho LL, Cielo CA, Bagarollo MF. Perception of parents on the quality of life in voice and clinical outcomes in dysphonic children before and after speech therapy group. Distúrb. Comun. 2013;25(1):81-90.

10. McAllister AM, Granqvist $S$, Sjölander $P$, Sundberg J. Child voice and noise: a pilot study of noise in day cares and the effects on 10 children's voice quality according to perceptual evaluation. J Voice. 2009;23(5):587-93.

11. Cardin PN, Roulstone S, Norhstone K. The prevalence of childhood dysphonia: a crosssectional study. J Voice. 2006;20(4):623-30.

12. Paixao CLB, Siqueira LTD, Coelho AC, Brasolotto $A G$, Silverio KCA. Is there agreement between parents and children about their vocal behavior? Distúrb. Comun. 2015;27(4):750-9.

13. Maia AA, Gama ACC, Michalick-Triginelli MF. Relação entre transtorno do déficit de atenção/ hiperatividade, dinâmica familiar, disfonia e nódulo vocal em crianças. Rev Cienc Med. 2006;15(5):379-89.

14. Tezcaner CZ, Ozgursoy SK, Sati I, Dursun G. Changes after voice therapy in objective and subjective voice measurements of pediatric patients with vocal nodules. Eur Arch Otorhinolaryngol. 2009;266(12):1923-7.

15. Takeshita TK, Aguiar-Ricz L, Isaac ML, Ricz $\mathrm{H}$, Anselmo-Lima W. Comportamento vocal de crianças em idade pré-escolar. Arq Int Otorrinolaringol. 2009;13(3):252-8.

16. Maia AA, Gama ACC, Kümmer AM. Behavioral characteristics of dysphonic children: integrative literature review. CoDAS. 2014;26(2):159-63.
17. Tavares ELM, Labio RB, Martins RHG. Estudo normativo dos parâmetros acústicos vocais de crianças de 4 a 12 anos de idade sem sintomas vocais: estudo piloto. Braz J Otorhinolaryngol. 2010;76(4):485-90.

18. Braga JN, Oliveira DSF, Sampaio TMM. Frequência fundamental da voz de crianças. Rev. CEFAC. 2009;11(1):119-26.

19. Behlau M. Consensus auditory-perceptual evaluation of voice (CAPE-V), ASHA 2003. Rev Soc Bras Fonoaudiol. 2004;9(3):187-9.

20. Martins PC, Couto TE, Gama ACC. Auditoryperceptual evaluation of the degree of vocal deviation: correlation between the Visual Analogue Scale and Numerical Scale. CoDAS. 2015;27(3):279-84.

21. Dornelles S, Jotz GP, Guilherme A. Correlação entre avaliação perceptiva auditiva e nasofibroscopia em crianças sem queixa vocal. Rev AMRIGS. 2007;51(2):121-7.

22. Lopes LW, Lima ILB, Azevedo EHM, Silva MFBL, Silva POC. Acoustic analysis of children's voices: phonatory deviation diagram contributions. Rev. CEFAC. 2015;17(4):1173-83.

23. Baravieira PB, Brasolotto AG, Montagnoli NA, Silvério KCA, Yamasaki R, Behlau M. Auditoryperceptual evaluation of rough and breathy voices: correspondence between analogical visual and numerical scale. CoDAS. 2016;28(2):163-7.

24. Behlau M, Madazio G, Feijó D, Pontes P. Avaliação de voz. In: Behlau M (org). Voz: O Livro do Especialista. Vol 1. Rio de Janeiro: Revinter, 2008. p. 85-176.

25. Capellari VM, Cielo CA. Vocal acoustic characteristics in pre-school aged children. Rev Bras Otorrinolaringol. 2008;74(2):265-72.

26. Viegas F, Viegas D, Atherino CCT, Baeck HE. Frequência fundamental das 7 vogais orais do português em vozes de crianças. Rev. CEFAC. 2010;12(4):563-70.

27. Lopes LW, Lima ILB, Almeida LNA, Cavalcante DP, Almeida AAF. Severity of voice disorders in children: correlations between perceptual and acoustic data. J Voice. 2012;26(6):819. e7- e12.

28. Steffen N, Moschetti MB. Parâmetros acústicos de jitter e shimmer em 248 crianças de 6 a 10 anos. Rev Bras Otorrinolaringol. 1997;63(4):329-34. 
29. Jotz GP, Cervantes O, Settani FAP, Angelis EC. Acoustic measures for the detection of hoarseness in children. Arq Int Otorrinolaringol. 2006;10(1):14-20.

30. Martins RHG, Ribeiro CBH, Melo BMZF, Branco AB, Tavares ELM. Dysphonia in children. J Voice. 2012;26(5):674.17-20. 